\title{
Prompt and delayed gamma rays induced by epithermal and fast neutrons with indium
}

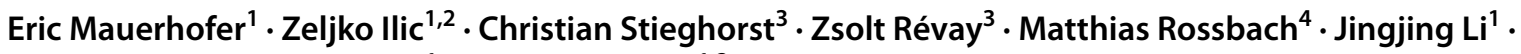 \\ Tsitohaina H. Randriamalala ${ }^{1}$. Thomas Brückel ${ }^{1,2}$
}

Received: 3 September 2021 / Accepted: 4 November 2021 / Published online: 2 December 2021

(c) The Author(s) 2021

\begin{abstract}
The emission of prompt and delayed gamma rays from $(n, \gamma)$ and $\left(n, n^{\prime} \gamma\right)$ reactions induced by irradiation of indium with epithermal and fast neutrons was investigated with the instrument FaNGaS operated at Heinz-Maier-Leibnitz Zentrum (MLZ) in Garching. The average neutron energy of the neutron spectrum was $2.30 \mathrm{MeV}$. The measurement was done at an angle of $90^{\circ}$ between neutron beam and detector. A total of 136 prompt gamma lines from which 42 are related to the capture of epithermal and fast neutrons and 94 to the inelastic scattering of fast neutrons were detected together with the delayed gamma lines of the activation products ${ }^{113 \mathrm{~m}} \mathrm{In},{ }^{114 \mathrm{~m} 2} \mathrm{In},{ }^{115 \mathrm{~m}} \mathrm{In},{ }^{116 \mathrm{~m} 2} \mathrm{In}$ and ${ }^{116 \mathrm{~m}} \mathrm{In}$. Intensities and neutron spectrum averaged isotopic partial cross section of the gamma lines are presented. Additionally the neutron spectrum averaged cross sections of the reactions, ${ }^{113} \operatorname{In}\left(\mathrm{n}, \mathrm{n}^{\prime}\right){ }^{113 \mathrm{~m}} \operatorname{In},{ }^{113} \operatorname{In}(\mathrm{n}, \gamma){ }^{114 \mathrm{~m} 2} \operatorname{In},{ }^{115} \operatorname{In}\left(\mathrm{n}, \mathrm{n}^{\prime}\right){ }^{15 \mathrm{~m}} \operatorname{In},{ }^{115} \operatorname{In}(\mathrm{n}, \gamma){ }^{116 \mathrm{~m} 2} \operatorname{In}$ and ${ }^{115} \operatorname{In}(\mathrm{n}, \gamma){ }^{116 \mathrm{~m}} \operatorname{In}$ were determined from the corresponding delayed gamma rays of the formed isotopes as $143 \pm 22,288 \pm 13194 \pm 18,201 \pm 10$ and $508 \pm 24$ $\mathrm{mb}$ respectively. The various results obtained were found consistent with the literature data. However, our measurement indicate the need to reevaluate the cross section of the ${ }^{115} \operatorname{In}(\mathrm{n}, \gamma)^{116 \mathrm{~m} 2} \operatorname{In}$ reaction for thermal neutrons.
\end{abstract}

Keywords Epithermal and fast neutrons $\cdot$ Indium $\cdot$ Neutron capture $\cdot$ Inelastic scattering $\cdot$ Cross section

\section{Introduction}

According to a series of recent white papers on nuclear data [1-3], improved knowledge on inelastic scattering of fast neutrons i.e. $\left(n, n^{\prime} \gamma\right)$-reactions are required for various applications in nuclear science and technology such as chemical analysis with neutron interrogation systems, design of fast neutron reactors and radiation protection. Fast-neutron-induced reactions, $\left(\mathrm{n}, \mathrm{n}^{\prime} \gamma\right)-$ or $(\mathrm{n}, \mathrm{p})-,(\mathrm{n}, \alpha)$ - and $(\mathrm{n}, 2 \mathrm{n})$-reactions can be investigated with the instrument FaNGaS (Fast Neutron induced Gamma Spectrometry) [4-6] installed at MLZ to

Eric Mauerhofer

e.mauerhofer@fz-juelich.de

1 Jülich Centre for Neutron Science, Forschungszentrum Jülich GmbH, 52425 Jülich, Germany

2 Lehrstuhl Für Experimentalphysik IVc, RWTH Aachen University, 52056 Aachen, Germany

3 Heinz Maier-Leibnitz Zentrum (MLZ), Technische Universität München, Lichtenbergstr, 85748 Garching, Germany

4 Im Heidehof, 42, 52372 Kreuzau, Germany perform elemental analysis of large samples by measurement of prompt and delayed gamma rays from interaction with fast neutrons. The latter are produced by a highly enriched-uranium $\left(93 \%{ }^{235} \mathrm{U}\right)$ convertor plate plunged into the reactor pool and extracted through a beam port and a set of collimators into an experimental bunker used for medical application (MEDAPP). Neutron-induced gamma radiation is detected with a wellshielded high-purity germanium detector mounted perpendicular to the neutron beam axis. Beside further development of FaNGaS to increase the sensitivity of prompt gamma-ray detection we aim to develop a modern comprehensive catalogue on (n,n' $\gamma)$-reactions by verifying and extending the only available database in this field: the "Atlas of Gamma-rays from the Inelastic Scattering of Reactor Fast Neutrons" published in 1978 by Demidov et al. [7]. From this Atlas a relational database of inelastic neutron scattering $\left(n, n^{\prime} \gamma\right)$ data has been recently developed [8]. The suitability of FaNGaS to provide reliable and accurate data for (n,n' $\gamma)$-reactions was demonstrated first by measuring prompt gamma rays generated by inelastic scattering of fast neutrons on natural iron [6]. Thanks to the modern design of the FaNGaS instrument, it was possible to identify 33 additional and 11 falsely identified compared 
to Demidov catalogue. In the present work, we report on the measurement of prompt and delayed gamma rays produced by capture of epithermal and fast neutrons and by inelastic scattering of fast neutrons on indium. Gamma-ray intensities and, partial and neutron spectrum-averaged reaction cross sections for indium isotopes are determined and compared with literature data.

\section{Theory}

Prompt gamma rays of indium are induced mainly from neutron capture via the ${ }^{115} \operatorname{In}(\mathrm{n}, \gamma)^{116} \mathrm{In}$ reaction and from inelastic scattering of fast neutrons via the ${ }^{115} \operatorname{In}\left(n, n^{\prime}\right)^{115} \operatorname{In}$ and ${ }^{113} \operatorname{In}\left(\mathrm{n}, \mathrm{n}^{\prime}\right)^{113}$ In reactions. Delayed gamma rays are emitted from the decay of ${ }^{116 \mathrm{~m} 2} \mathrm{In}\left(T_{1 / 2}=2.18 \mathrm{~s}\right)$ and ${ }^{116 \mathrm{~m}} \mathrm{In}$ $\left(T_{1 / 2}=54.29 \mathrm{~m}\right)$ formed by neutron capture $\left({ }^{116 \mathrm{~m} 2} \mathrm{In}\right.$ decays to $100 \%$ into $\left.{ }^{116 \mathrm{~m}} \mathrm{In}\right)$ and from the decay of ${ }^{115 \mathrm{~m}} \mathrm{In}\left(T_{1 / 2}=4.49 \mathrm{~h}\right)$ generated by inelastic scattering of fast neutrons $\left({ }^{115 \mathrm{~m}}\right.$ In decays to $95 \%$ into ${ }^{115} \mathrm{In}$ by isomeric conversion and to $5 \%$ into ${ }^{115} \mathrm{Sn}$ by beta decay). The reaction rates $R\left(\right.$ atom $\left.^{-1} \mathrm{~s}^{-1}\right)$ and the effective cross sections $\sigma\left(\mathrm{cm}^{2}\right)$ for the aforementioned reactions and for the $\operatorname{In}(\mathrm{n}$, tot) reaction may be estimated as follows:

$R=\sum_{i} \sigma\left(E_{i}\right) \cdot \Phi\left(E_{i}\right)$

and

$\sigma=\frac{R}{\sum_{i} \Phi\left(E_{i}\right)}$

where $\Phi\left(E_{i}\right)$ is the neutron flux in the neutron energy bin $i$ and $\sigma\left(E_{i}\right)$ the reaction cross section averaged over the neutron energy bin $i$. The neutron energy spectrum at sample position measured in our previous work [6] by means of the foil activation technique is shown in Fig. 1. It may be divided into three components designated as thermal $\left(10^{-10} \mathrm{MeV}<E_{i}<1.4210^{-7} \mathrm{MeV}\right)$, epithermal $\left(1.4210^{-7} \mathrm{MeV}<E_{i}<0.06 \mathrm{MeV}\right)$ and fast $\left(0.06 \mathrm{MeV}<E_{i}<20 \mathrm{MeV}\right)$ neutron energy regions with the respective neutron fluxes, $(9.4 \pm 2.8) \times 10^{2} \mathrm{~cm}^{-2} \mathrm{~s}^{-1}$, $(1.85 \pm 0.09) \times 10^{6} \mathrm{~cm}^{-2} \mathrm{~s}^{-1}$ and $(1.40 \pm 0.05) \times 10^{8} \mathrm{~cm}^{-2} \mathrm{~s}^{-1}$. The integral neutron flux is $(1.42 \pm 0.05) \times 10^{8} \mathrm{~cm}^{-2} \mathrm{~s}^{-1}$. The average energy of the neutron spectrum is $2.30 \mathrm{MeV}$. The values of $\sigma\left(E_{i}\right)$ were produced with the GROUPR module of the NJOY Nuclear Data Processing System [9] from the Evaluated Nuclear Data File databases ENDF/BVIII.0 [10] for the ${ }^{115} \operatorname{In}(\mathrm{n}, \gamma){ }^{116} \operatorname{In}$, and ${ }^{115} \operatorname{In}\left(\mathrm{n}, \mathrm{n}^{\prime}\right){ }^{115} \mathrm{In}$ and ${ }^{113} \operatorname{In}\left(\mathrm{n}, \mathrm{n}^{\prime}\right)^{113}$ In reactions and ENDF/B-VI.8 [11] for the $\operatorname{In}(n, t o t)$-reaction. Their neutron energy dependence is shown together with the neutron energy spectrum in Fig. 1. The reaction rates $R$ and the effective cross sections $\sigma$ determined by means of Eqs. (1) and (2), respectively, for the epithermal and fast region of the neutron spectrum

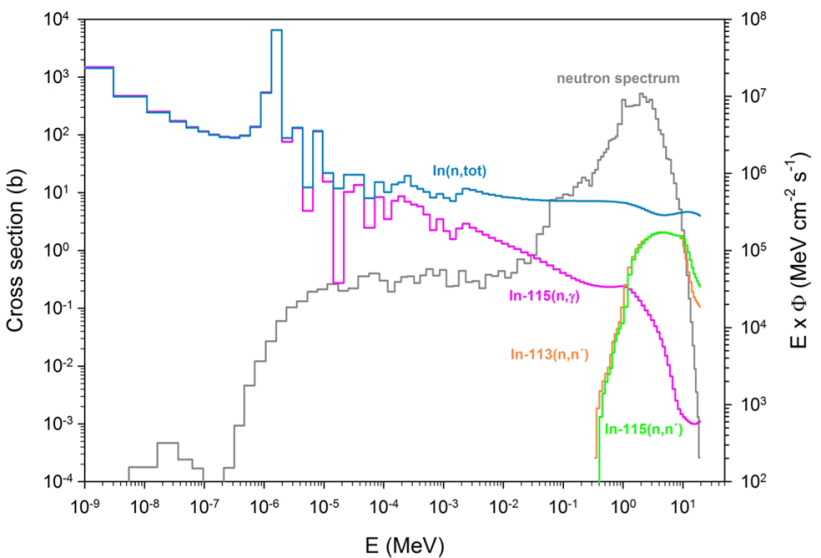

Fig. 1 Neutron energy spectra of FaNGaS at sample position (right scale of y-axis) and neutron energy dependence of the cross section $\boldsymbol{\sigma}\left(\boldsymbol{E}_{\boldsymbol{i}}\right)$ averaged over the neutron energy bin i for the ${ }^{115} \operatorname{In}(\mathrm{n}, \gamma)^{116} \mathrm{In}$, ${ }^{115} \operatorname{In}\left(\mathrm{n}, \mathrm{n}^{\prime}\right)^{115} \operatorname{In},{ }^{113} \operatorname{In}\left(\mathrm{n}, \mathrm{n}^{\prime}\right)^{113} \operatorname{In}$ and $\operatorname{In}(\mathrm{n}, \mathrm{tot})$ reactions (left scale of $\mathrm{y}$ axis)

are given Table 1. Due to the low thermal neutron flux, the reaction rate of ${ }^{115} \operatorname{In}(\mathrm{n}, \gamma)^{116} \operatorname{In}$ induced by thermal neutrons was neglected. The rates produced by capture of epithermal and fast neutrons represent $74 \%$ and $26 \%$ of the total reaction rate, respectively. The reaction rates of ${ }^{115} \operatorname{In}\left(n, n^{\prime}\right)^{115} \operatorname{In}$ and ${ }^{113} \operatorname{In}\left(n, n^{\prime}\right){ }^{113} \operatorname{In}$ are about two times higher than the total reaction rate of ${ }^{115} \operatorname{In}(\mathrm{n}, \gamma){ }^{116} \mathrm{In}$. The effective cross sections $\left\langle\sigma_{e p i}\right\rangle$ estimated for capture of epithermal neutrons are $31 \pm 2 \mathrm{~b}$ for ${ }^{115} \operatorname{In}(\mathrm{n}, \gamma)^{116} \mathrm{In}$ and $38 \pm 3 \mathrm{~b}$ for the $\operatorname{In}(\mathrm{n}, \mathrm{tot})$ reaction. It should be mentioned here that these values are not comparable to the resonance integrals obtained for a reactor spectrum since our spectrum does not follow 1/E dependence in the epithermal region. The effective cross sections $\left\langle\sigma_{\text {fast }}\right\rangle$ determined for capture and for inelastic scattering of fast neutrons agree well with the values given in JANIS (Java-based Nuclear Data Information System) Book of neutron induced cross section [12] (see Table 1). The neutron spectrum-averaged cross sections $\left\langle\sigma_{\text {int }}\right\rangle$ are given in the last column of Table 1.

\section{Experimental}

Prompt and delayed gamma radiation generated by irradiation of a high-purity indium foil of natural composition (mass: $1.334 \mathrm{~g}$, surface: $2.7 \times 2.7 \mathrm{~cm}^{2}$, thickness: $0.025 \mathrm{~cm}$ ) with epithermal and fast neutrons was investigated with the FaNGaS instrument described in [6]. The shape of the neutron beam was quadratic with a cross sectional area of $6 \times 6 \mathrm{~cm}^{2}$ at sample position. The neutron spectrum at sample position is given in Fig. 1. The gamma-ray spectrum was recorded during neutron irradiation with the FaNGaS spectrometer composed of a well-shielded electromechanically cooled HPGe-detector 
Table 1 Reaction rates $R$ and effective cross sections $\langle\sigma\rangle$ for the reactions ${ }^{115} \operatorname{In}(\mathrm{n}, \gamma)^{116} \operatorname{In},{ }^{115} \operatorname{In}\left(\mathrm{n}, \mathrm{n}^{\prime}\right)^{115} \mathrm{In},{ }^{113} \operatorname{In}\left(\mathrm{n}, \mathrm{n}^{\prime}\right)^{113} \mathrm{In}$ and $\operatorname{In}(\mathrm{n}, \mathrm{tot})$ calculated by mean of Eq. (1) and Eq. (2), respectively and

\begin{tabular}{|c|c|c|c|c|c|c|}
\hline \multirow{3}{*}{$\begin{array}{l}\text { Neutron-energy range } \\
\phi\end{array}$} & \multirow{2}{*}{\multicolumn{2}{|c|}{$\frac{1.410^{-7}-0.06 \mathrm{MeV} \text { (epithermal) }}{1.85(9) 10^{6} \mathrm{~cm}^{-2} \mathrm{~s}^{-1}}$}} & \multirow{2}{*}{\multicolumn{2}{|c|}{$\frac{0.06-20 \mathrm{MeV} \text { (fast) }}{1.40(5) 10^{8} \mathrm{~cm}^{-2} \mathrm{~s}^{-1}}$}} & \multirow{2}{*}{\multicolumn{2}{|c|}{$\frac{10^{-10}-20 \mathrm{MeV} \text { (integral) }}{1.42(5) 10^{8} \mathrm{~cm}^{-2} \mathrm{~s}^{-1}}$}} \\
\hline & & & & & & \\
\hline & $\mathrm{R}_{\text {epi }}\left(\right.$ atom $\left.^{-1} \mathrm{~s}^{-1}\right)$ & $<\sigma_{\text {epi }}>(b)$ & $\mathrm{R}_{\text {fast }}\left(\right.$ atom $\left.^{-1} \mathrm{~s}^{-1}\right)$ & $<\sigma_{\text {fast }}>$ (b) & $\mathrm{R}_{\text {int }}\left(\right.$ atom $\left.^{-1} \mathrm{~s}^{-1}\right)$ & $<\sigma_{\text {int }}>(b)$ \\
\hline${ }^{115} \operatorname{In}(\mathrm{n}, \gamma)^{116} \mathrm{In}$ & $5.76(35) 10^{-17}$ & $31(2)$ & $2.03(20) 10^{-17}$ & $0.14(2) 0.16(1)^{\mathrm{a}}$ & $7.80(55) 10^{-17}$ & $0.55(4)$ \\
\hline${ }^{113} \operatorname{In}\left(\mathrm{n}, \mathrm{n}^{\prime}\right)^{113} \operatorname{In}$ & - & - & $1.40(6) 10^{-16}$ & $1.00(6) 0.98(9)^{\mathrm{a}}$ & $1.40(6) 10^{-16}$ & $0.98(5)$ \\
\hline${ }^{115} \operatorname{In}\left(\mathrm{n}, \mathrm{n}^{\prime}\right)^{115} \mathrm{In}$ & - & - & $1.46(6) 10^{-16}$ & $1.04(6) 1.01(6)^{\mathrm{a}}$ & $1.46(6) 10^{-16}$ & $1.03(5)$ \\
\hline $\operatorname{In}(n, t o t)$ & $7.05(51) 10^{-17}$ & $38(3)$ & $7.86(63) 10^{-16}$ & $5.6(5) 5.795^{\mathrm{b}}$ & $8.57(68) 10^{-16}$ & $6.0(5)$ \\
\hline $\mathrm{f}_{\mathrm{n}}$ & $0.982(2)$ & & $0.9973(4)$ & & $0.9971(3)$ & \\
\hline
\end{tabular}

$\phi$ is the integral neutron flux in the considered neutron-energy range. a: cross sections evaluated in JANIS (mean value from various nuclear data libraries) [12]. b: cross section calculated from JENDL-4.0 [24, 25]

with a relative efficiency of 50\% and a resolution (FWHM) of $2.1 \mathrm{keV}$ at $1.33 \mathrm{MeV}$ [4]. The measurement was performed at an angle of $90^{\circ}$ between neutron beam direction and detector. The sample-to-detector distance was $67 \mathrm{~cm}$. The foil was irradiated for $9.91 \mathrm{~h}$ with it surface perpendicular to the neutron beam and counted for $7.46 \mathrm{~h}$ (live time). The spectrum was analyzed with the software HYPERMET-PC [13]. The analysis of the beam background carried out in a previous work [6] was used to facilitate the identification of gamma lines. The spectra of indium and beam background are shown together for various energy ranges in Figs. 2 and 3. In comparison to the beam background, the count rates of background lines in the indium spectrum were higher by a mean factor $1.11 \pm 0.02$ due to the scattering of fast neutrons towards the spectrometer. The identification of capture gamma rays of ${ }^{115}$ In was performed using the PGAA (Prompt Gamma Activation Analysis) database [14]. The prompt gamma rays arising from inelastic neutron scattering were assigned to ${ }^{115}$ In or ${ }^{113}$ In using the database NutDat 2.8 [15] and nuclear data provided in [16].

\section{Method}

The net peak area of a prompt gamma ray of energy $E_{\gamma}$ induced by neutron capture or by inelastic neutron scattering, $P_{E \gamma}$, may be expressed by the following relation:

$P_{E \gamma}=\frac{m}{M} \cdot N_{A} \cdot h \cdot \varepsilon_{E \gamma} \cdot\left\langle\sigma_{E \gamma}\right\rangle \cdot \Phi \cdot t_{c} \cdot f_{n} \cdot f_{E \gamma}$

where $m(\mathrm{~g})$ is the amount of element, $M\left(\mathrm{~g} \mathrm{~mol}^{-1}\right)$ the molar mass of the element, $N_{A}$ the Avogadro number, $h$ the abundance of the isotope considered, $\varepsilon_{E \gamma}$ the full energy peak efficiency, $\left\langle\sigma_{E \gamma}\right\rangle\left(\mathrm{cm}^{2}\right)$ the neutron spectrum averaged isotopic cross section for gamma ray production, $\Phi\left(\mathrm{cm}^{-2} \mathrm{~s}^{-1}\right)$ the corresponding integral neutron flux, $t_{c}(\mathrm{~s})$ the counting (live) time, $f_{n}$ a factor for neutron self-shielding and $f_{E \gamma}$ a factor for gamma-ray self-absorption. In the case of $\left(n, n^{\prime} \gamma\right)$-reactions, neutron self-shielding factors $f_{n}$ calculated by means of Eq. (7), for the considered neutron-energy ranges 

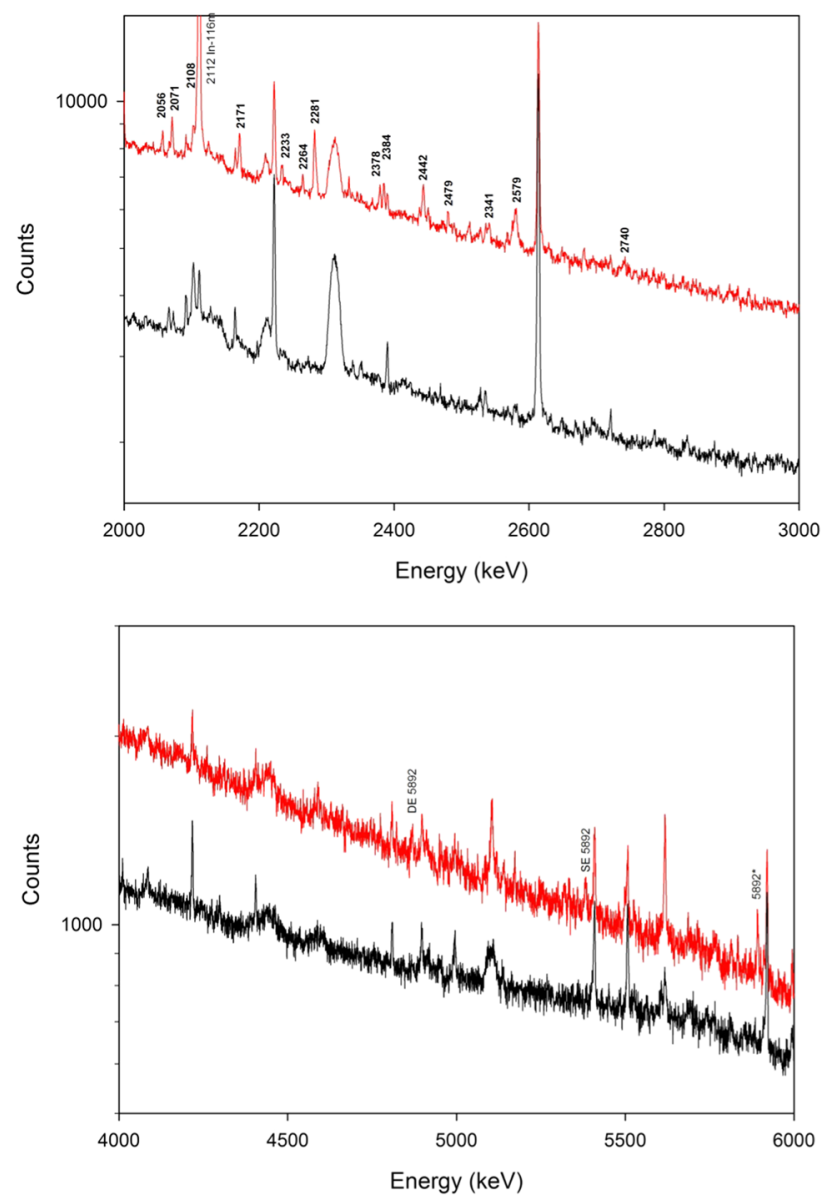

Fig. 3 Gamma ray spectra in the energy range 2000-6000 keV acquired during 26,850 s for the indium foil (red) and during 46,454 s for the beam background (black). Prompt and delayed gamma rays induced by capture of resonance and fission neutrons are labelled with asterisks. Prompt gamma rays issued from inelastic scattering of fission neutrons are written in bold

the gamma emission is anisotropic and therefore $\left\langle\sigma_{E \gamma}\right\rangle$ depends on the measurement angle i.e. the angle between the neutron beam direction and the detector.

The net peak area of a delayed gamma ray of energy $E_{\gamma}$ measured during irradiation may be given by:

$P_{E \gamma}=\frac{m}{M} \cdot N_{A} \cdot h \cdot \varepsilon_{E \gamma} \cdot\left\langle\sigma_{E \gamma}\right\rangle \cdot \Phi \cdot f_{n} \cdot f_{E \gamma} \cdot g\left(t_{b}, t_{c}, t_{1 / 2}\right)$

with

$g\left(t_{b}, t_{c}, t_{1 / 2}\right)=\frac{t_{c}}{t_{b}} \cdot \int_{0}^{t_{b}}\left(1-e^{-\frac{\ln 2 \cdot t}{t_{1} / 2}}\right) d t=\left[t_{c}-\frac{t_{c} \cdot t_{1 / 2}}{t_{b} \cdot \ln 2} \cdot\left(1-e^{-\frac{\ln 2 \cdot t_{b}}{t_{1 / 2}}}\right)\right]$

where $t_{b}$ is the irradiation (real) time, $t_{c}$ the counting (live) time and $t_{1 / 2}$ the half-live of activation product. In both relations (3) and (4), the averaged isotopic cross section for gamma-ray production $\left\langle\sigma_{E \gamma}\right\rangle$ is linked to the effective cross

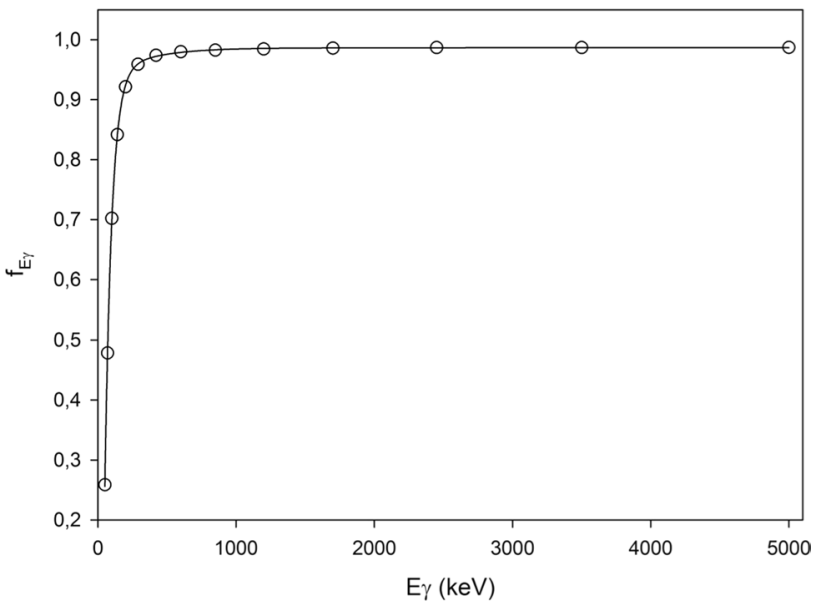

Fig. 4 Dependence of the gamma self-absorption $f_{E \gamma}$ on the gamma energy E $\gamma$ The solid line represent the fit of the data with Eq. (8)

section $\langle\sigma\rangle$ of the considered reaction through the intensity of the gamma ray $I_{E \gamma}$ as

$\left\langle\sigma_{E \gamma}\right\rangle=I_{E \gamma} \cdot\langle\sigma\rangle$

The gamma ray intensity contains the contribution of internal conversion. The neutron self-shielding factor $f_{n}$ for a pure element foil in a neutron beam may be calculated as follows [17]:

$f_{n}=\frac{1-e^{-\langle\sigma\rangle \cdot \rho_{a} \cdot d}}{\langle\sigma\rangle \cdot \rho_{a} \cdot d}$

with $\langle\sigma\rangle$ the effective elemental cross section for the (n,tot)reaction, $\rho_{a}$ the atomic density (atoms $/ \mathrm{cm}^{3}$ ) and $d$ the foil thickness $(\mathrm{cm})$. The $f_{n}$-values for the indium foil $\left(\rho_{a}=3.83\right.$ $10^{22}$ atoms $/ \mathrm{cm}^{3}, d=0.025 \mathrm{~cm}$ ) calculated by means of (7) for different neutron energy regions using the corresponding estimated effective cross sections for the In(n,tot)-reaction, are given in the last row of Table 1. As expected, the neutron-shielding factors are close to unity since the foil is very thin. Thus, corrections for neutron absorption and multiple scattering may be neglected.

The gamma-ray self-absorption of the indium foil was determined numerically using the Monte Carlo transport simulation code PHITS (Particle and Heavy Ion Transport code System) Version 3.02 [18]. Several mono-energetic photons of energies ranging from $50 \mathrm{keV}$ to $5 \mathrm{MeV}$ were considered and generated homogeneously over the indium foil volume. A spherical detector surrounding the foil was used to count the outgoing photons at the same single energy bin as for the primary photons and thus, to deduce the selfattenuation ratio. The dependence of the gamma-ray selfabsorption $f_{E \gamma}$ on the gamma energy $E_{\gamma}$ is shown on Fig. 4 
and can be approximated with the following semi-empirical function:

$f_{E \gamma}=a_{0}+a_{1} \cdot\left(1-e^{-a_{2} \cdot E_{\gamma}}\right)+a_{3}\left(1-e^{-a_{4} \cdot E_{\gamma}}\right)$

with $a_{0}=-0.9403, a_{1}=0.0556, a_{2}=3.301 \cdot 10^{-3}, a_{3}=1.8712$, $a_{4}=0.0201$ and $E_{\gamma}$ in keV.

\section{Gamma rays from neutron capture}

42 capture gamma rays and 10 delayed gamma rays ( 9 for ${ }^{116 \mathrm{~m}} \mathrm{In}$ and 1 for ${ }^{116 \mathrm{~m} 2} \mathrm{In}$ ) were observed in the spectrum. They are given in Table 2 and 3, together with their respective isotopic cross sections for gamma-ray production $\left\langle\sigma_{E \gamma}\right\rangle$ calculated by means of Eq. (3) and Eq. (4), respectively with an integral neutron flux of $(1.42 \pm 0.05) \times 10^{8} \mathrm{~cm}^{-2} \mathrm{~s}^{-1}$. The intensities of the prompt gamma rays $I_{E \gamma}$ calculated by means of Eq. (6) using the integral cross section $\left\langle\sigma_{\text {int }}\right\rangle=0.55 \pm 0.04$ $\mathrm{b}$ determined for the ${ }^{115} \operatorname{In}(\mathrm{n}, \gamma){ }^{116} \operatorname{In}$ reaction (see Table 1) are given in column 4 of Table 2. For comparison, the isotopic cross sections for production of the prompt and delayed gamma rays by thermal neutron capture $\sigma_{E \gamma, t h}$ deduced from the PGAA (Prompt Gamma Activation Analysis) database [14] are also given Table 2 and 3 and the intensities of the prompt gamma rays $I_{E \gamma, t h}$ calculated from the adopted thermal neutron cross section $202 \pm 2$ b [19] given in column 6 of Table 2. The intensities of the delayed gamma rays of ${ }^{116 \mathrm{~m} I n}$ and ${ }^{116 \mathrm{~m} 2}$ In are taken from the WWW Table of Radioactive Isotopes [20] and given in column 3 of Table 3. Concerning the prompt gamma rays, the intensities of the two data sets are comparable within their uncertainties, except for the lines at 60.9, 94.04+94.06 and $5891.9 \mathrm{keV}$ which show large deviations. The average value of the $I_{E \gamma} / I_{E \gamma, t h}$ -ratios is $0.95 \pm 0.11$ and the average value of the $\left\langle\sigma_{E \gamma}\right\rangle / \sigma_{E \gamma, t h}$ -ratios, $(2.58 \pm 0.32) \times 10^{-3}$ fit well the ratio of the neutron capture reaction cross sections, $(2.72 \pm 0.20) \times 10^{-3}$. The overall relationship between $I_{E \gamma}$ and $I_{E \gamma, t h}$ is shown in Fig. 5 and can be expressed by:

$I_{E \gamma}=a \cdot\left(I_{E \gamma, t h}\right)^{b}$

with $a=0.92 \pm 0.03$ and $b=0.98 \pm 0.03$. Further investigations must be carried out to understand the large differences observed for the aforementioned prompt gamma lines.

The isotope cross sections of delayed gamma rays are used to determine the integral cross sections of the reactions ${ }^{115} \operatorname{In}(\mathrm{n}, \gamma)^{116 \mathrm{~m}} \operatorname{In}$ and ${ }^{115} \operatorname{In}(\mathrm{n}, \gamma)^{116 \mathrm{~m} 2} \mathrm{In}$ by means of Eq. (6). The $\left\langle\sigma_{\text {int }}\right\rangle$-values obtained for the ${ }^{115} \operatorname{In}(\mathrm{n}, \gamma)^{116 \mathrm{~m}} \mathrm{In}$ reaction from the various gamma rays of ${ }^{116 \mathrm{~m}} \mathrm{In}$ agree well with each other (see column 5 in Table 4) providing a mean value of $508 \pm 20 \mathrm{mb}$. This value in conjugation with the average value of the $\left\langle\sigma_{E \gamma}\right\rangle / \sigma_{E \gamma, t h}$ ratios, $(3.13 \pm 0.14) \times 10^{-3}$, leads to a thermal cross section of $163 \pm 9 \mathrm{~b}$ which is in good agreement with the adopted value, $162.3 \pm 0.7 \mathrm{~b}$ [19]. The $\left\langle\sigma_{\text {int }}\right\rangle$-value obtained for the ${ }^{115} \operatorname{In}(\mathrm{n}, \gamma)^{116 \mathrm{~m} 2} \mathrm{In}$ reaction is $201 \pm 10 \mathrm{mb}$ and leads with a $\left\langle\sigma_{E \gamma}\right\rangle / \sigma_{E \gamma, t h}$-ratio of $(4.54 \pm 0.30) \times 10^{-3}$ to a thermal cross section of $44 \pm 4 \mathrm{~b}$ which disagrees with literature data, $81 \pm 8 \mathrm{~b}[19,21], 83 \pm 8$ $b$ [22] and $92 \pm 14$ [23]. Therefore, the thermal cross section of the ${ }^{115} \operatorname{In}(\mathrm{n}, \gamma)^{116 \mathrm{~m} 2} \operatorname{In}$ reaction must be reevaluated.

\section{Gamma rays from neutron inelastic scattering}

A total of 94 prompt gamma lines issued from the inelastic scattering of fast neutrons were identified, 69 associated to ${ }^{115} \mathrm{In}$ and 25 to ${ }^{113} \mathrm{In}$ (see Tables 2 and 3). Interferences from capture gamma lines were corrected determining their contributions by means of Eqs. (3), (6) and (9). All indium lines reported in the work of Demidov et al. [7] were observed and additional lines were also detected (13 for ${ }^{115}$ In and 2 for ${ }^{113} \mathrm{In}$ ). Some lines given in the Demidov Atlas are not mentioned in the database NuDat 2.8. The gamma lines listed at energies 149.7, 284.7, 288.7, 293.6, 306.1, 376.2 and $633.8 \mathrm{keV}$ are probably capture gamma lines of ${ }^{115} \mathrm{In}$ as the delayed gamma rays of ${ }^{116 \mathrm{~m}}$ In and ${ }^{116 \mathrm{~m} 2} \mathrm{In}$ are visible in the indium spectrum given in the Demidov Atlas. The line at $312 \mathrm{keV}$ can be assigned to the decay of ${ }^{114 \mathrm{~m} 2} \mathrm{In}$ $\left(T_{1 / 2}=43.1 \mathrm{~ms}, E \gamma=311.7 \mathrm{keV}, I \gamma=86.6 \%\right)$ formed by neutron capture. From our measurement we derive by means of Eq. (4) a neutron spectrum averaged cross section of $288 \pm 13 \mathrm{mb}$ for the ${ }^{113} \operatorname{In}(\mathrm{n}, \gamma)^{114 \mathrm{~m} 2} \mathrm{In}$ reaction. The line at $336 \mathrm{keV}$ can be related to the decay of ${ }^{115 \mathrm{~m}} \operatorname{In}\left(T_{1 / 2}=4.486 \mathrm{~h}\right.$, $E \gamma=336.2 \mathrm{keV}, I \gamma=45.8 \%)$ produced by fast neutrons including also the capture gamma ray of ${ }^{115} \mathrm{In}$ at $335.4 \mathrm{keV}$ as interference. The latter represents in our case $36 \pm 4 \%$ of the measured count rate of the $336-\mathrm{keV}$ line. After correction of this interference we obtain by means of Eq. (5) a fast neutron averaged cross section of $194 \pm 18 \mathrm{mb}$ for the ${ }^{115} \operatorname{In}\left(\mathrm{n}, \mathrm{n}^{\prime}\right)^{115 \mathrm{~m}} \mathrm{In}$ reaction which agrees well with the values of $188 \pm 11 \mathrm{mb}$ [26] and $162.6 \pm 13 \mathrm{mb}$ [27]. Therefore, the $336-\mathrm{keV}$ line cannot be considered as a prompt gamma line arising from the inelastic scattering of neutrons as given in Demidov Atlas. The line at $391 \mathrm{keV}$ can be associated to the decay of ${ }^{113 \mathrm{~m}} \mathrm{In}\left(T_{1 / 2}=1.658 \mathrm{~h}, E \gamma=391.7 \mathrm{keV}, I \gamma=64.2 \%\right)$ induced by fast neutrons. From our measurement we determine by means of Eq. (5) a fast neutron averaged cross section of $143 \pm 22 \mathrm{mb}$ for the ${ }^{113} \operatorname{In}\left(\mathrm{n}, \mathrm{n}^{\prime}\right)^{113 \mathrm{~m}} \mathrm{In}$ reaction which agrees with the value of $133.7 \pm 10.7 \mathrm{mb}$ [27].

The intensity of the prompt gamma rays $\left(I_{R}\right)$ were calculated relative to the $933-\mathrm{keV}$ line of ${ }^{115} \mathrm{In}(100 \%)$, and they are given with the values $\left(I_{R D}\right)$ determined in [7] in Tables 4 and 5. The relationship between the relative intensities is given in Fig. 6. The values were fitted with semi-empirical function: 
Table 2 Prompt gamma rays of ${ }^{115}$ In induced by neutron capture
This work Capture of resonance and fission neutrons

\begin{tabular}{|c|c|c|c|c|c|}
\hline$E_{\gamma}(\mathrm{keV})$ & $\begin{array}{l}P_{E \gamma} / \varepsilon E_{\gamma} \cdot f_{\gamma}(\gamma \\
\text { (Count) }\end{array}$ & $\left\langle\sigma_{E \gamma}\right\rangle(\mathrm{mb})$ & $I_{E \gamma}(\%)$ & $\sigma_{E \gamma, t h}(\mathrm{~b})$ & $I_{E \gamma, t h}(\%)$ \\
\hline 60.9 & $8.2 \pm 0.2$ & $32.1 \pm 1.4$ & $5.84 \pm 0.49$ & $16.5 \pm 0.1$ & $8.16 \pm 0.09$ \\
\hline 85.6 & $16.2 \pm 0.8$ & $63.5 \pm 3.8$ & $11.5 \pm 1.1$ & $23.1 \pm 0.2$ & $11.4 \pm 0.1$ \\
\hline $96.04+96.06$ & $14.3 \pm 0.6$ & $56 \pm 3$ & $10.2 \pm 0.9$ & $37.6 \pm 0.2$ & $18.6 \pm 0.2$ \\
\hline 126.4 & $2.12 \pm 0.09$ & $8.3 \pm 0.5$ & $1.51 \pm 0.14$ & $4.2 \pm 0.3$ & $2.08 \pm 0.15$ \\
\hline 149.7 & $0.57 \pm 0.03$ & $2.2 \pm 0.1$ & $0.40 \pm 0.03$ & $0.72 \pm 0.05$ & $0.36 \pm 0.02$ \\
\hline 155.3 & $1.64 \pm 0.08$ & $6.4 \pm 0.4$ & $1.16 \pm 0.11$ & $2.6 \pm 0.2$ & $1.28 \pm 0.10$ \\
\hline 163.8 & $0.47 \pm 0.05$ & $1.8 \pm 0.2$ & $0.33 \pm 0.04$ & $0.70 \pm 0.05$ & $0.35 \pm 0.02$ \\
\hline 171.1 & $2.03 \pm 0.09$ & $7.9 \pm 0.5$ & $1.44 \pm 0.14$ & $3.6 \pm 0.3$ & $1.78 \pm 0.15$ \\
\hline 173.9 & $2.67 \pm 0.11$ & $10.5 \pm 0.6$ & $1.91 \pm 0.18$ & $4.3 \pm 0.3$ & $2.13 \pm 0.15$ \\
\hline 175.1 & $0.89 \pm 0.11$ & $3.5 \pm 0.4$ & $0.64 \pm 0.09$ & $1.17 \pm 0.07$ & $0.58 \pm 0.04$ \\
\hline 186.2 & $18.32 \pm 0.72$ & $72 \pm 4$ & $13.1 \pm 1.2$ & $27.8 \pm 0.2$ & $13.8 \pm 0.2$ \\
\hline 202.6 & $2.05 \pm 0.21$ & $8.0 \pm 0.9$ & $1.45 \pm 0.19$ & $2.8 \pm 0.2$ & $1.39 \pm 0.10$ \\
\hline 213.6 & $0.32 \pm 0.11$ & $1.3 \pm 0.4$ & $0.24 \pm 0.08$ & $0.67 \pm 0.05$ & $0.33 \pm 0.02$ \\
\hline $234.6+235.3$ & $4.34 \pm 0.21$ & $17 \pm 1$ & $3.09 \pm 0.29$ & $5.9 \pm 0.4$ & $2.92 \pm 0.20$ \\
\hline 240.3 & $0.34 \pm 0.07$ & $1.3 \pm 0.3$ & $0.24 \pm 0.06$ & $0.46 \pm 0.03$ & $0.23 \pm 0.01$ \\
\hline 267.9 & $0.37 \pm 0.05$ & $1.4 \pm 0.2$ & $0.25 \pm 0.04$ & $0.54 \pm 0.04$ & $0.27 \pm 0.02$ \\
\hline 272.9 & $24.0 \pm 0.4$ & $94 \pm 4$ & $17.1 \pm 1.4$ & $34.6 \pm 0.2$ & $17.1 \pm 0.2$ \\
\hline 284.9 & $3.13 \pm 0.21$ & $12 \pm 1$ & $2.18 \pm 0.24$ & $4.7 \pm 0.3$ & $2.33 \pm 0.15$ \\
\hline 290.9 & $1.56 \pm 0.10$ & $6.1 \pm 0.4$ & $1.11 \pm 0.10$ & $2.7 \pm 0.2$ & $1.33 \pm 0.10$ \\
\hline 295.5 & $1.66 \pm 0.10$ & $6.5 \pm 0.4$ & $1.18 \pm 0.11$ & $3.0 \pm 0.2$ & $1.48 \pm 0.10$ \\
\hline 298.7 & $7.28 \pm 1.04$ & $28 \pm 4$ & $5.09 \pm 0.81$ & $9.8 \pm 0.7$ & $4.85 \pm 0.35$ \\
\hline 305.1 & $0.93 \pm 0.10$ & $3.6 \pm 0.4$ & $0.65 \pm 0.09$ & $1.35 \pm 0.09$ & $0.66 \pm 0.04$ \\
\hline 375.9 & $2.37 \pm 0.10$ & $9.3 \pm 0.5$ & $1.69 \pm 0.15$ & $2.8 \pm 0.2$ & $1.39 \pm 0.10$ \\
\hline $384.8+385.1$ & $9.59 \pm 0.31$ & $37 \pm 2$ & $6.72 \pm 0.60$ & $16 \pm 1$ & $7.92 \pm 0.50$ \\
\hline 422.2 & $0.95 \pm 0.20$ & $3.7 \pm 0.8$ & $0.67 \pm 0.15$ & $1.8 \pm 0.1$ & $0.89 \pm 0.05$ \\
\hline 433.7 & $4.52 \pm 0.30$ & $18 \pm 1$ & $3.27 \pm 0.30$ & $6.3 \pm 0.4$ & $3.12 \pm 0.19$ \\
\hline 471.3 & $3.28 \pm 0.20$ & $12.8 \pm 0.9$ & $2.33 \pm 0.23$ & $4.5 \pm 0.3$ & $2.23 \pm 0.15$ \\
\hline 475.9 & $1.16 \pm 0.17$ & $4.5 \pm 0.7$ & $0.82 \pm 0.14$ & $2.0 \pm 0.1$ & $0.99 \pm 0.05$ \\
\hline $517.9+518.1$ & $4.32 \pm 0.19$ & $16.9 \pm 0.7$ & $3.07 \pm 0.26$ & $6.2 \pm 0.5$ & $3.07 \pm 0.25$ \\
\hline 521.5 & $1.41 \pm 0.09$ & $5.5 \pm 0.4$ & $1.00 \pm 0.10$ & $2.0 \pm 0.1$ & $0.99 \pm 0.05$ \\
\hline 548.7 & $1.35 \pm 0.08$ & $5.3 \pm 0.4$ & $0.96 \pm 0.10$ & $2.1 \pm 0.1$ & $1.04 \pm 0.05$ \\
\hline 556.8 & $3.78 \pm 0.20$ & $14.8 \pm 0.9$ & $2.69 \pm 0.25$ & $4.9 \pm 0.3$ & $2.42 \pm 0.15$ \\
\hline 577.5 & $1.27 \pm 0.08$ & $5.0 \pm 0.4$ & $0.91 \pm 0.10$ & $2.0 \pm 0.1$ & $0.99 \pm 0.05$ \\
\hline 608.4 & $2.52 \pm 0.30$ & $10 \pm 1$ & $1.82 \pm 0.22$ & $3.7 \pm 0.3$ & $1.83 \pm 0.15$ \\
\hline 633.7 & $1.16 \pm 0.10$ & $4.5 \pm 0.4$ & $0.82 \pm 0.09$ & $1.6 \pm 0.1$ & $0.79 \pm 0.05$ \\
\hline 634.3 & $1.07 \pm 0.08$ & $4.2 \pm 0.3$ & $0.76 \pm 0.08$ & $1.7 \pm 0.1$ & $0.84 \pm 0.05$ \\
\hline 992.1 & $0.58 \pm 0.05$ & $2.3 \pm 0.2$ & $0.42 \pm 0.05$ & $0.95 \pm 0.07$ & $0.47 \pm 0.03$ \\
\hline 5891.9 & $0.67 \pm 0.07$ & $2.6 \pm 0.3$ & $0.47 \pm 0.06$ & $2.2 \pm 0.1$ & $1.09 \pm 0.05$ \\
\hline
\end{tabular}

$E_{\gamma}$ is the gamma-ray energy, $P_{\mathrm{E} \gamma} / \varepsilon E_{\gamma} \cdot f_{\gamma}$ the net count in the gamma-ray peak divided by the full-energypeak efficiency and the gamma-ray self-absorption factor, $\left\langle\sigma_{E \gamma}\right\rangle$ the neutron spectrum-averaged isotopic cross section for gamma ray production determined with Eq. (3) and $I_{E \gamma}$ the gamma-ray intensity calculated by means of Eq. (6). 
Table 3 Delayed gamma rays induced by neutron capture

\begin{tabular}{|c|c|c|c|c|c|c|}
\hline & $E_{\gamma}(\mathrm{keV})$ & $I_{E \gamma}(\%)$ & \multicolumn{2}{|c|}{$\begin{array}{l}P_{E \gamma} / \varepsilon E_{\gamma} \cdot f_{\gamma}\left(\times 10^{-8}\right)\left\langle\sigma_{E \gamma}\right\rangle(\mathrm{mb}) \\
\text { (Count) }\end{array}$} & $\left\langle\sigma_{\text {int }}\right\rangle(\mathrm{b})$ & $\sigma_{E \gamma, t h}(\mathrm{~b})$ \\
\hline \multicolumn{7}{|l|}{${ }^{116 m}$ In } \\
\hline & 138.3 & 3.29 & $3.9 \pm 0.3$ & $17.6 \pm 1.5$ & $0.53 \pm 0.04$ & $5.34 \pm 0.19$ \\
\hline & 416.9 & 27.7 & $30 \pm 1$ & $135 \pm 6$ & $0.49 \pm 0.02$ & $44.9 \pm 0.2$ \\
\hline & 463.3 & 0.83 & $0.89 \pm 0.08$ & $4.0 \pm 0.4$ & $0.48 \pm 0.05$ & $1.33 \pm 0.08$ \\
\hline & 818.7 & 11.5 & $14.0 \pm 0.5$ & $63 \pm 3$ & $0.55 \pm 0.03$ & $18.6 \pm 0.7$ \\
\hline & 1097.3 & 56.2 & $64.7 \pm 1.9$ & $291 \pm 13$ & $0.52 \pm 0.02$ & $91.2 \pm 0.2$ \\
\hline & 1293.6 & 84.4 & $96.9 \pm 2.9$ & $437 \pm 20$ & $0.52 \pm 0.02$ & $137 \pm 3$ \\
\hline & 1507.6 & 10.0 & $10.7 \pm 0.4$ & $48.3 \pm 2.5$ & $0.48 \pm 0.02$ & $16.2 \pm 0.5$ \\
\hline & 1752.2 & 2.46 & $2.7 \pm 0.1$ & $12.2 \pm 0.6$ & $0.50 \pm 0.02$ & $3.99 \pm 0.12$ \\
\hline & 2111.8 & 15.5 & $17.3 \pm 0.6$ & $78.0 \pm 3.9$ & $0.50 \pm 0.02$ & $25.2 \pm 0.7$ \\
\hline \multicolumn{7}{|l|}{${ }^{116 \mathrm{~m} 2} \mathrm{In}$} \\
\hline & 162.4 & 37.2 & $19.1 \pm 0.7$ & $74.8 \pm 3.8$ & $0.20 \pm 0.01$ & $16.5 \pm 0.8$ \\
\hline
\end{tabular}

$E_{\gamma}$ is the gamma-ray energy, $I_{E \gamma}$ the gamma-ray intensity, $P_{\mathrm{E} \gamma} / \varepsilon E_{\gamma} \cdot f_{\gamma}$ the net count in the gamma-ray peak divided by the full-energy-peak efficiency and the gamma-ray self-absorption factor, $\left\langle\sigma_{E \gamma}\right\rangle$ the neutron spectrum-averaged isotopic cross section for gamma ray production by Eq. (4), $\left\langle\sigma_{\text {int }}\right\rangle$ is the neutron spectrum-averaged cross section for the reaction calculated by means of Eq. (6) and $\sigma_{E \gamma, t h}$ is the isotopic cross section for gamma ray production from thermal neutron capture [14].

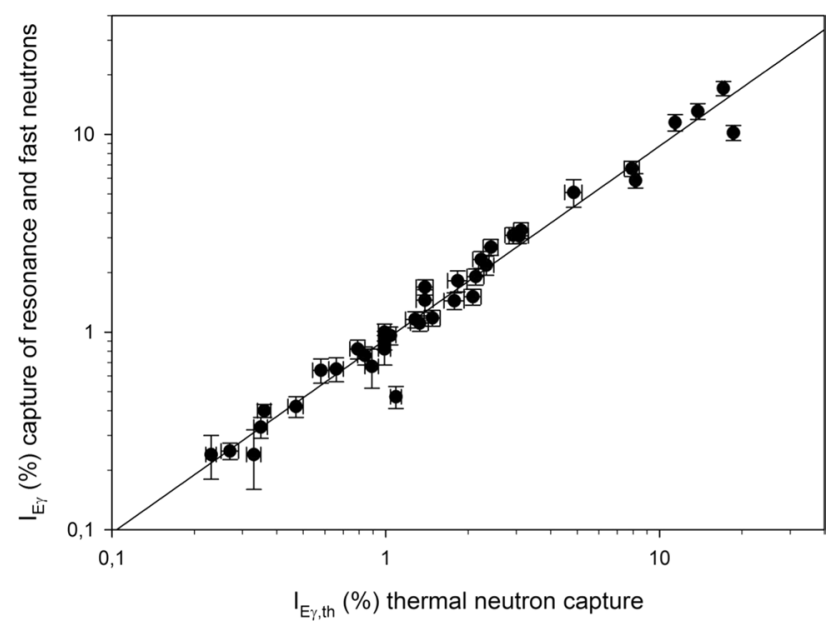

Fig. 5 Relationship between the absolute intensities $\boldsymbol{I}_{E \gamma}$ of prompt gamma rays issued from the capture of resonance and fast neutrons by ${ }^{115}$ In and the absolute intensities $\boldsymbol{I}_{E \gamma, \text { th }}$ of same prompt gamma rays induced by thermal neutron capture The solide line represents the fit of the data with Eq. (9)

$I_{R}=a \cdot\left(I_{R D}\right)^{b}$

with $a=1.21 \pm 0.06$ and $b=0.94 \pm 0.03$. The consistency between the two sets of data is shown in Fig. 7 in the form of a histogram of the residuals in unit of standard deviation $[\sigma]$ calculated as

$R=\frac{I_{R}-I_{R D}}{\sqrt{\left(s_{I_{R}}\right)^{2}+\left(s_{I_{R D}}\right)^{2}}}$
The fit of the histogram with a Gaussian shows an agreement between the data at the $1.6 \sigma$ level, implying a reasonable consistency. The shift of the Gaussian centroid to a value of 0.68 indicates a probable systematic effect. The fast neutron spectrum averaged isotopic cross sections for gamma ray production calculated by means of Eq. (3) with a neutron flux of $(1.40 \pm 0.05) \times 10^{8} \mathrm{~cm}^{-2} \mathrm{~s}^{-1}$ are given in column 4 of Tables 4 and 5 .

\section{Conclusions}

Prompt gamma ray emission induced by capture of epithermal and fast neutrons as well as by inelastic scattering of fast neutrons on indium was measured with the FaNGaS instrument operated at FRM II. The measurement was carried out at an angle of $90^{\circ}$ between the fast neutron beam and the detector with an integral neutron flux of $1.42 \times 10^{8} \mathrm{~cm}^{-2} \mathrm{~s}^{-1}$ and a epithermal flux of $1.85 \times 10^{6} \mathrm{~cm}^{-2} \mathrm{~s}^{-1}$ at sample position. A total of 42 neutron capture gamma lines issued from the ${ }^{115} \operatorname{In}(n, \gamma){ }^{116}$ In reaction were detected. Their absolute intensities were calculated with a spectrum-averaged reaction cross section of $0.55 \mathrm{~b}$ and found to be comparable to the absolute intensities of the corresponding thermal neutron capture lines derived from PGAA database [14]. From the delayed gamma rays of ${ }^{116 \mathrm{~m}} \mathrm{In}$ and ${ }^{116 \mathrm{~m} 2} \mathrm{In}$, spectrum-averaged cross sections of $508 \pm 24 \mathrm{mb}$ and $201 \pm 10 \mathrm{mb}$ were determined for the ${ }^{115} \operatorname{In}(\mathrm{n}, \gamma)^{116 \mathrm{~m}} \operatorname{In}$ and ${ }^{115} \operatorname{In}(\mathrm{n}, \gamma){ }^{116 \mathrm{~m} 2} \operatorname{In}$ reactions, respectively. Additionally, we show the necessity to reevaluate the thermal cross section of the ${ }^{115} \operatorname{In}(n$, 
Table 4 Prompt gamma rays of ${ }^{115}$ In induced by inelastic scattering of fast neutrons

\begin{tabular}{|c|c|c|c|c|c|c|}
\hline \multicolumn{4}{|l|}{ This work } & \multicolumn{2}{|c|}{ From Demidov Atlas [7] } & \multirow[t]{2}{*}{$\mathrm{R}$} \\
\hline$E_{\gamma}(\mathrm{keV})$ & $\begin{array}{l}P_{E \gamma} / \varepsilon E_{\gamma} \cdot f_{\gamma}\left(\times 10^{-8}\right) \\
\text { (Count) }\end{array}$ & $\mathrm{I}_{\mathrm{R}}($ relative $)(\%)$ & $\left\langle\sigma_{E \gamma}\right\rangle(\mathrm{mb})$ & $E_{\gamma}(\mathrm{keV})$ & $I_{R D}($ relative $)(\%)$ & \\
\hline $146.04 \pm 0.03$ & $2.25 \pm 0.07$ & $4.02 \pm 0.19$ & $199 \pm 9$ & $146.4 \pm 0.2$ & $7.2 \pm 0.8$ & -3.87 \\
\hline $230.98 \pm 0.05$ & $1.28 \pm 0.08$ & $2.28 \pm 0.16$ & $5.09 \pm 0.37$ & $231.6 \pm 0.2$ & $2.8 \pm 0.4$ & -1.21 \\
\hline $260.34 \pm 0.03$ & $20.35 \pm 0.63$ & $36.3 \pm 1.7$ & $81 \pm 4$ & $260.84 \pm 0.10$ & $42.0 \pm 5.0$ & -1.08 \\
\hline $315.56 \pm 0.05$ & $1.36 \pm 0.08$ & $2.43 \pm 0.17$ & $5.40 \pm 0.37$ & $315.9 \pm 0.3$ & $2.8 \pm 0.3$ & -1.07 \\
\hline $321.26 \pm 0.05$ & $1.64 \pm 0.12^{\mathrm{a}}$ & $2.92 \pm 0.24$ & $6.51 \pm 0.53$ & $321.2 \pm 0.3$ & $3.6 \pm 0.3$ & -1.77 \\
\hline $335.48 \pm 0.05^{\mathrm{b}}$ & $10.90 \pm 0.94^{\mathrm{a}}$ & $19.46 \pm 1.82$ & $87.70 \pm 8.18$ & $336.30 \pm 0.10$ & $35.0 \pm 3.0^{\mathrm{c}}$ & - \\
\hline $345.89 \pm 0.04$ & $2.48 \pm 0.10$ & $4.42 \pm 0.24$ & $9.85 \pm 0.53$ & $345.4 \pm 0.2$ & $5.5 \pm 0.7$ & -1.46 \\
\hline $353.36 \pm 0.14$ & $1.51 \pm 0.17$ & $2.70 \pm 0.32$ & $6.00 \pm 0.71$ & $354.3 \pm 0.3$ & $2.4 \pm 0.3$ & 0.68 \\
\hline $363.7 \pm 0.1$ & $0.70 \pm 0.08$ & $1.25 \pm 0.15$ & $2.78 \pm 0.33$ & $364.4 \pm 0.4$ & $1.1 \pm 0.2$ & 0.66 \\
\hline $443.57 \pm 0.05$ & $1.85 \pm 0.31$ & $3.30 \pm 0.56$ & $7.35 \pm 1.25$ & $444.4 \pm 0.2$ & $2.7 \pm 0.3$ & 0.94 \\
\hline $479.55 \pm 0.07$ & $1.54 \pm 0.10$ & $2.75 \pm 0.20$ & $6.11 \pm 0.45$ & - & - & - \\
\hline $483.64 \pm 0.04$ & $18.25 \pm 0.52$ & $32.58 \pm 1.48$ & $72.52 \pm 3.31$ & $484.49 \pm 0.10$ & $26.0 \pm 4.0$ & 1.54 \\
\hline $491.53 \pm 0.03$ & $11.61 \pm 0.47$ & $20.73 \pm 1.12$ & $46.14 \pm 2.49$ & $492.42 \pm 0.10$ & $17.0 \pm 3.0$ & 1.16 \\
\hline $526.99 \pm 0.03$ & $2.28 \pm 0.08$ & $4.07 \pm 0.20$ & $9.06 \pm 0.45$ & $528.0 \pm 0.2^{\mathrm{d}}$ & $5.9 \pm 0.4$ & -4.09 \\
\hline $529.17 \pm 0.05$ & $0.87 \pm 0.05$ & $1.55 \pm 0.10$ & $3.45 \pm 0.23$ & - & - & - \\
\hline $544.8 \pm 0.3$ & $0.45 \pm 0.07$ & $0.80 \pm 0.13$ & $1.79 \pm 0.28$ & $546.1 \pm 0.4$ & $1.2 \pm 0.2$ & -1.68 \\
\hline $550.20 \pm 0.05$ & $1.23 \pm 0.10$ & $2.20 \pm 0.19$ & $4.89 \pm 0.43$ & $550.4 \pm 0.3$ & $1.9 \pm 0.3$ & 0.84 \\
\hline $603.41 \pm 0.04$ & $2.35 \pm 0.61$ & $4.20 \pm 1.10$ & $9.33 \pm 2.44$ & $604.0 \pm 0.2$ & $3.8 \pm 0.3$ & 0.35 \\
\hline $626.08 \pm 0.03$ & $2.76 \pm 0.10$ & $4.93 \pm 0.25$ & $10.97 \pm 0.56$ & $627.3 \pm 0.2$ & $3.1 \pm 0.3$ & 4.68 \\
\hline $700.06 \pm 0.5$ & $1.90 \pm 0.10$ & $3.39 \pm 0.21$ & $7.55 \pm 0.48$ & $701.0 \pm 0.3$ & $3.2 \pm 0.3$ & 0.52 \\
\hline $704.54 \pm 0.03$ & $10.09 \pm 0.30$ & $18.01 \pm 0.84$ & $40.10 \pm 1.86$ & $705.64 \pm 0.10$ & $19.0 \pm 2.0$ & -0.56 \\
\hline $749.36 \pm 0.04$ & $3.71 \pm 0.13$ & $6.62 \pm 0.33$ & $14.71 \pm 0.74$ & $749.8 \pm 0.1$ & $5.9 \pm 0.3$ & 1.61 \\
\hline $763.69 \pm 0.04$ & $1.96 \pm 0.09$ & $3.50 \pm 0.20$ & $7.79 \pm 0.45$ & $765.6 \pm 0.2$ & $2.7 \pm 0.2$ & 2.83 \\
\hline $770.48 \pm 0.08$ & $1.83 \pm 0.20$ & $3.27 \pm 0.37$ & $7.27 \pm 0.83$ & $771.0 \pm 0.2$ & $2.7 \pm 0.2$ & 1.35 \\
\hline $781.5 \pm 0.1$ & $0.71 \pm 0.20$ & $1.27 \pm 0.36$ & $2.82 \pm 0.80$ & $781.3 \pm 0.3$ & $1.9 \pm 0.2$ & -1.53 \\
\hline $796.45 \pm 0.04$ & $1.71 \pm 0.07$ & $3.05 \pm 0.16$ & $6.79 \pm 0.37$ & $797.7 \pm 0.2$ & $3.0 \pm 0.2$ & 0.19 \\
\hline $830.1 \pm 0.04$ & $2.75 \pm 0.10$ & $4.91 \pm 0.25$ & $10.93 \pm 0.56$ & - & - & - \\
\hline $845.57 \pm 0.05$ & $5.13 \pm 0.18$ & $9.16 \pm 0.46$ & $20.39 \pm 1.03$ & $846.1 \pm 0.2$ & $6.6 \pm 0.3$ & 4.66 \\
\hline $866.96 \pm 0.07$ & $2.01 \pm 0.30$ & $3.6 \pm 0.2$ & $8.00 \pm 1.22$ & - & - & - \\
\hline $880.05 \pm 0.05$ & $1.83 \pm 0.10$ & $3.27 \pm 0.21$ & $7.27 \pm 0.47$ & $879.0 \pm 0.2$ & $3.4 \pm 0.2$ & -0.45 \\
\hline $897.0 \pm 0.2$ & $1.52 \pm 0.20$ & $2.71 \pm 0.37$ & $6.04 \pm 0.82$ & $897.5 \pm 0.2$ & $1.9 \pm 0.2$ & 1.92 \\
\hline $914.52 \pm 0.05$ & $1.26 \pm 0.08$ & $2.25 \pm 0.16$ & $5.00 \pm 0.36$ & $915.8 \pm 0.3$ & $1.2 \pm 0.2$ & 4.10 \\
\hline $933.092 \pm 0.008$ & $56 \pm 2.0$ & 100.0 & $222 \pm 11$ & $933.8 \pm 0.2$ & 100.0 & - \\
\hline $937.4 \pm 0.1$ & $3.04 \pm 0.41$ & $5.42 \pm 0.8$ & $12.08 \pm 1.68$ & - & - & - \\
\hline $940.64 \pm 0.03$ & $14.33 \pm 0.41$ & $25.59 \pm 1.17$ & $56.95 \pm 2.61$ & $941.28 \pm 0.10$ & $28.0 \pm 4.0$ & -0.58 \\
\hline $954.7 \pm 0.1$ & $2.64 \pm 0.10$ & $4.71 \pm 0.24$ & $10.49 \pm 0.55$ & $955.7 \pm 0.2$ & $3.5 \pm 0.3$ & 3.15 \\
\hline $964.4 \pm 0.1$ & $1.88 \pm 0.13$ & $3.36 \pm 0.26$ & $7.47 \pm 0.58$ & $964.3 \pm 0.2$ & $3.4 \pm 0.3$ & -0.10 \\
\hline $979.88 \pm 0.04$ & $2.44 \pm 0.41$ & $4.36 \pm 0.75$ & $9.70 \pm 1.66$ & $980.6 \pm 0.2$ & $4.0 \pm 0.3$ & 0.44 \\
\hline $1003.4 \pm 0.2$ & $0.28 \pm 0.05$ & $0.50 \pm 0.09$ & $1.11 \pm 0.20$ & $1002.8 \pm 0.7$ & $0.43 \pm 0.11$ & 0.49 \\
\hline $1076.96 \pm 0.09$ & $9.44 \pm 0.30$ & $16.86 \pm 0.80$ & $37.51 \pm 1.79$ & $1077.5 \pm 0.2$ & $11 . \pm 1.0$ & 4.57 \\
\hline $1131.91 \pm 0.03$ & $43.64 \pm 1.01$ & $77.93 \pm 3.31$ & $173.42 \pm 7.38$ & $1132.62 \pm 0.10$ & $72.0 \pm 5.0$ & 0.99 \\
\hline $1149.9 \pm 0.1$ & $0.96 \pm 0.07$ & $1.71 \pm 0.14$ & $3.81 \pm 0.31$ & $1150.0 \pm 0.6$ & $0.69 \pm 0.20$ & 4.18 \\
\hline $1250.6 \pm 0.2$ & $0.50 \pm 0.06$ & $0.89 \pm 0.11$ & $1.99 \pm 0.25$ & $1250.5 \pm 0.6$ & $0.82 \pm 0.14$ & 0.39 \\
\hline $1290.50 \pm 0.04$ & $27.39 \pm 4.06$ & $48.91 \pm 7.46$ & $108.8 \pm 16.6$ & $1290.4 \pm 0.8$ & $47 \pm 4$ & 0.22 \\
\hline $1448.10 \pm 0.03$ & $11.76 \pm 0.40$ & $21.00 \pm 1.04$ & $46.73 \pm 2.30$ & $1448.95 \pm 0.20$ & $18.0 \pm 2$ & 1.33 \\
\hline $1462.39 \pm 0.03$ & $8.11 \pm 1.01$ & $14.48 \pm 1.87$ & $32.23 \pm 4.17$ & $1462.96 \pm 0.20$ & $12 \pm 2$ & 0.90 \\
\hline $1485.43 \pm 0.03$ & $10.75 \pm 0.30$ & $19.19 \pm 0.87$ & $42.72 \pm 1.93$ & $1486.24 \pm 0.20$ & $16 \pm 2$ & 1.46 \\
\hline
\end{tabular}


Table 4 (continued)

\begin{tabular}{|c|c|c|c|c|c|c|}
\hline \multicolumn{4}{|l|}{ This work } & \multicolumn{2}{|c|}{ From Demidov Atlas [7] } & \multirow[t]{2}{*}{$\mathrm{R}$} \\
\hline$E_{\gamma}(\mathrm{keV})$ & $\begin{array}{l}P_{E \gamma} / \varepsilon E_{\gamma} \cdot f_{\gamma}\left(\times 10^{-8}\right) \\
\text { (Count) }\end{array}$ & $\mathrm{I}_{\mathrm{R}}($ relative $)(\%)$ & $\left\langle\sigma_{E \gamma}\right\rangle(\mathrm{mb})$ & $E_{\gamma}(\mathrm{keV})$ & $I_{R D}($ relative $)(\%)$ & \\
\hline $1496.38 \pm 0.03$ & $3.95 \pm 0.10$ & $7.05 \pm 0.31$ & $15.70 \pm 0.69$ & $1496.9 \pm 0.2$ & $6.1 \pm 0.3$ & 2.20 \\
\hline $1569.0 \pm 0.2$ & $0.26 \pm 0.04$ & $0.46 \pm 0.07$ & $1.03 \pm 0.16$ & $1568.2 \pm 0.7$ & $0.58 \pm 0.12$ & -0.86 \\
\hline $1601.11 \pm 0.04$ & $5.07 \pm 0.20$ & $9.05 \pm 0.48$ & $20.15 \pm 1.07$ & $1601.3 \pm 0.5$ & $7.4 \pm 0.7$ & 1.94 \\
\hline $1606.83 \pm 0.03$ & $4.15 \pm 0.10$ & $7.41 \pm 0.32$ & $16.49 \pm 0.71$ & $1607.0 \pm 0.5$ & $5.7 \pm 0.7$ & 2.22 \\
\hline $1736.01 \pm 0.04$ & $2.61 \pm 0.09$ & $4.66 \pm 0.23$ & $10.37 \pm 0.51$ & $1737.2 \pm 0.3$ & $3.5 \pm 0.4$ & 2.51 \\
\hline $1937.23 \pm 0.09$ & $0.64 \pm 0.04$ & $1.14 \pm 0.08$ & $2.54 \pm 0.18$ & $1937.2 \pm 0.6$ & $1.4 \pm 0.3$ & -0.84 \\
\hline $1970.41 \pm 0.04$ & $2.20 \pm 0.09$ & $3.96 \pm 0.2$ & $8.74 \pm 0.47$ & $1971.9 \pm 0.3$ & $3.8 \pm 0.2$ & 0.56 \\
\hline $1976.4 \pm 0.1$ & $0.47 \pm 0.04$ & $0.84 \pm 0.08$ & $1.87 \pm 0.17$ & - & - & - \\
\hline $1998.89 \pm 0.04$ & $1.62 \pm 0.05$ & $2.89 \pm 0.14$ & $6.43 \pm 0.30$ & $1999.9 \pm 0.3$ & $2.4 \pm 0.2$ & 2.01 \\
\hline $2056.8 \pm 0.1$ & $0.46 \pm 0.04$ & $0.82 \pm 0.08$ & $1.83 \pm 0.17$ & $2058.4 \pm 1.6$ & $0.28 \pm 0.14$ & 3.35 \\
\hline $2071.03 \pm 0.08$ & $0.86 \pm 0.06$ & $1.53 \pm 0.12$ & $3.42 \pm 0.28$ & $2070.8 \pm 0.8$ & $1.9 \pm 0.2$ & -1.58 \\
\hline $2108.4 \pm 0.1$ & $1.52 \pm 0.20$ & $2.71 \pm 0.37$ & $6.04 \pm 0.82$ & - & - & - \\
\hline $2170.87 \pm 0.08$ & $1.08 \pm 0.07$ & $1.93 \pm 0.14$ & $4.29 \pm 0.37$ & $2171.7 \pm 1.4$ & $1.0 \pm 0.3$ & 2.81 \\
\hline $2233.6 \pm 0.1$ & $0.36 \pm 0.06$ & $0.64 \pm 0.11$ & $1.43 \pm 0.24$ & $2244.5 \pm 1.7 !$ & $0.68 \pm 0.23$ & -0.16 \\
\hline $2264.4 \pm 0.1$ & $0.29 \pm 0.03$ & $0.52 \pm 0.06$ & $1.15 \pm 0.13$ & - & - & - \\
\hline $2281.86 \pm 0.07$ & $1.52 \pm 0.09$ & $2.71 \pm 0.18$ & $6.04 \pm 0.50$ & $2282.9 \pm 0.6$ & $2.4 \pm 0.2$ & 1.15 \\
\hline $2378.15 \pm 0.10$ & $0.50 \pm 0.06$ & $0.89 \pm 0.11$ & $1.98 \pm 0.26$ & $2381.2 \pm 1.3^{\mathrm{e}}$ & $2.2 \pm 0.5$ & -0.25 \\
\hline $2384.43 \pm 0.08$ & $0.65 \pm 0.06$ & $1.16 \pm 0.11$ & $2.58 \pm 0.28$ & & & \\
\hline $2442.89 \pm 0.08$ & $0.97 \pm 0.05$ & $1.73 \pm 0.24$ & $3.85 \pm 0.30$ & $2443.4 \pm 1.0$ & $1.6 \pm 0.4$ & 0.28 \\
\hline $2479.8 \pm 0.2$ & $0.34 \pm 0.04$ & $0.61 \pm 0.08$ & $1.35 \pm 0.18$ & - & - & - \\
\hline $2540.7 \pm 0.2$ & $0.42 \pm 0.04$ & $0.75 \pm 0.08$ & $1.67 \pm 0.19$ & - & - & - \\
\hline $2579.37 \pm 0.03$ & $0.88 \pm 0.09$ & $1.57 \pm 0.17$ & $3.49 \pm 0.38$ & - & - & - \\
\hline $2740.6 \pm 0.3$ & $0.32 \pm 0.05$ & $0.57 \pm 0.09$ & $1.27 \pm 0.21$ & - & - & - \\
\hline
\end{tabular}

$E_{\gamma}$ is the gamma-ray energy, $P_{\mathrm{E} \gamma} / \varepsilon E_{\gamma} \cdot f_{\gamma}$ the net count in the gamma-ray peak divided by the full-energy-peak efficiency and the gamma-ray selfabsorption factor, $\mathrm{I}_{\mathrm{R}}$ the relative intensity of the gamma-ray and $\left\langle\sigma_{E \gamma}\right\rangle$ the fission neutron spectrum averaged isotopic cross section for gamma ray production at an angle of $90^{\circ}$ between neutron beam and detector determined with Eq. (3). $\mathrm{R}$ is the residual calculated by means of Eq. (11).

${ }^{\mathrm{a}}$ corrected for contributions of neutron capture lines

${ }^{b}$ delayed gamma ray of ${ }^{115 \mathrm{~m}} \mathrm{In}$

cinterference from neutron capture probably not considered. Unresolved doublet

d 527 and $529 \mathrm{keV}$

e 2378 and $2384 \mathrm{keV}$

$\gamma)^{116 \mathrm{~m} 2}$ In reaction. A total of 94 prompt gamma lines arising from ${ }^{115} \operatorname{In}\left(\mathrm{n}, \mathrm{n}^{\prime}\right)^{115} \operatorname{In}$ and ${ }^{113} \operatorname{In}\left(\mathrm{n}, \mathrm{n}^{\prime}\right)^{113} \operatorname{In}$ reactions were observed and their relative intensities (using the $933 \mathrm{keV}$ gamma ray of ${ }^{115} \mathrm{In}$ as reference) and spectrum-averaged production cross sections were determined. Compared to the work of Demidov et al. [7], 15 gamma lines were detected additionally. Several lines mentioned in the Demidov Atlas were identified as neutron capture gamma lines or decay gamma lines of ${ }^{113 \mathrm{~m}} \mathrm{In},{ }^{114 \mathrm{~m} 2} \mathrm{In}$ and ${ }^{115 \mathrm{~m}} \mathrm{In}$. For the reactions ${ }^{113} \operatorname{In}\left(\mathrm{n}, \mathrm{n}^{\prime}\right)^{113 \mathrm{~m}} \operatorname{In},{ }^{113} \operatorname{In}(\mathrm{n}, \gamma){ }^{114 \mathrm{~m} 2} \operatorname{In}$ and ${ }^{115} \operatorname{In}\left(\mathrm{n}, \mathrm{n}^{\prime}\right)^{115 \mathrm{~m}} \mathrm{In}$ we 
Table 5 Prompt gamma rays of ${ }^{113}$ In induced by inelastic scattering of fast neutrons

\begin{tabular}{|c|c|c|c|c|c|c|}
\hline \multicolumn{4}{|l|}{ This work } & \multicolumn{2}{|c|}{ From demidov atlas [7] } & \multirow[t]{2}{*}{$\mathrm{R}$} \\
\hline$E_{\gamma}(\mathrm{keV})$ & $\begin{array}{l}\mathrm{P}_{\mathrm{E}_{\gamma}} / \varepsilon \mathrm{E}_{\gamma} \cdot f_{\mathrm{E}_{\gamma}} \\
\text { (relative) }(\%)\end{array}$ & $\mathrm{I}_{\mathrm{R}}$ (relative) $(\%)$ & $\left\langle\sigma_{E \gamma}\right\rangle(\mathrm{mb})$ & $E_{\gamma}(\mathrm{keV})$ & $I_{R}($ relative $)(\%)$ & \\
\hline $255.09 \pm 0.03$ & $1.4 \pm 0.2$ & $2.50 \pm 0.37$ & $124 \pm 18$ & $255.1 \pm 0.3$ & $1.7 \pm 0.5$ & 1.29 \\
\hline $311.77 \pm 0.03^{\mathrm{a}}$ & $2.82 \pm 0.10$ & $5.03 \pm 0.25$ & $250 \pm 12$ & $312.1 \pm 0.2$ & $3.2 \pm 0.3$ & - \\
\hline $390.95 \pm 0.06^{\mathrm{b}}$ & $0.79 \pm 0.12$ & $1.41 \pm 0.22$ & $92 \pm 14$ & $392.0 \pm 0.3$ & $1.5 \pm 0.3$ & - \\
\hline $537.44 \pm 0.07$ & $0.55 \pm 0.06$ & $0.98 \pm 0.11$ & $49 \pm 5$ & $538.82 \pm 0.5$ & $0.68 \pm 0.27$ & 1.03 \\
\hline $717.72 \pm 0.06$ & $1.58 \pm 0.15$ & $2.82 \pm 0.29$ & $137 \pm 14$ & $718.6 \pm 0.3$ & $1.6 \pm 0.2$ & 3.46 \\
\hline $728.13 \pm 0.04$ & $1.47 \pm 0.08$ & $2.62 \pm 0.17$ & $130 \pm 8$ & $729.4 \pm 0.2$ & $3.0 \pm 0.3$ & -1.10 \\
\hline $734.07 \pm 0.03$ & $6.82 \pm 0.23$ & $12.18 \pm 0.59$ & $605 \pm 30$ & $735.14 \pm 0.10$ & $12.0 \pm 2.0$ & 0.09 \\
\hline $757.91 \pm 0.05$ & $0.98 \pm 0.06$ & $1.75 \pm 0.12$ & $87 \pm 6$ & - & - & - \\
\hline $972.76 \pm 0.09$ & $0.91 \pm 0.06$ & $1.62 \pm 0.12$ & $81 \pm 6$ & $973.0 \pm 0.4$ & $0.57 \pm 0.15$ & 5.47 \\
\hline $1023.67 \pm 0.06$ & $1.70 \pm 0.09$ & $3.03 \pm 0.19$ & $150 \pm 9$ & $1024.1 \pm 0.2$ & $2.3 \pm 0.3$ & 2.06 \\
\hline $1039.33 \pm 0.05$ & $0.74 \pm 0.06$ & $1.32 \pm 0.12$ & $64 \pm 6$ & $1040.9 \pm 0.3$ & $1.5 \pm 0.2$ & -0.77 \\
\hline $1052.5 \pm 0.1$ & $1.28 \pm 0.12$ & $2.28 \pm 0.23$ & $111 \pm 11$ & $1052.8 \pm 0.2$ & $1.9 \pm 0.2$ & 1.25 \\
\hline $1142.49 \pm 0.05$ & $1.09 \pm 0.09$ & $1.95 \pm 0.17$ & $94 \pm 8$ & $1142.6 \pm 0.3$ & $1.5 \pm 0.2$ & 1.71 \\
\hline $1160.97 \pm 0.06$ & $1.62 \pm 0.11$ & $2.89 \pm 0.22$ & $140 \pm 11$ & $1160.7 \pm 0.2$ & $2.4 \pm 0.2$ & 1.65 \\
\hline $1172.58 \pm 0.05$ & $2.0 \pm 0.1$ & $3.57 \pm 0.22$ & $177 \pm 10$ & $1173.1 \pm 0.2$ & $3.6 \pm 0.3$ & -0.08 \\
\hline $1190.57 \pm 0.04$ & $1.46 \pm 0.07$ & $2.60 \pm 0.15$ & $129 \pm 7$ & $1191.0 \pm 0.2$ & $2.4 \pm 0.2$ & 0.80 \\
\hline $1238.58 \pm 0.05$ & $1.19 \pm 0.25$ & $2.12 \pm 0.45$ & $105 \pm 22$ & $1239.4 \pm 0.2$ & $1.8 \pm 0.2$ & 0.65 \\
\hline $1260.3 \pm 0.3$ & $0.85 \pm 0.14$ & $1.51 \pm 0.25$ & $75 \pm 13$ & $1259.7 \pm 0.6$ & $0.97 \pm 0.20$ & 1.69 \\
\hline $1271.4 \pm 0.06$ & $1.33 \pm 0.08$ & $2.37 \pm 0.16$ & $118 \pm 8$ & $1272.2 \pm 0.3$ & $1.8 \pm 0.2$ & 2.26 \\
\hline $1304.7 \pm 0.2$ & $0.31 \pm 0.08$ & $0.55 \pm 0.14$ & $27 \pm 7$ & $1305.4 \pm 0.6$ & $0.73 \pm 0.22$ & -0.69 \\
\hline $1316.3 \pm 0.08$ & $0.59 \pm 0.08$ & $1.05 \pm 0.15$ & $51 \pm 7$ & $1316.2 \pm 0.7$ & $0.46 \pm 0.09$ & 3.37 \\
\hline $1324.3 \pm 0.1$ & $0.80 \pm 0.09$ & $1.43 \pm 0.17$ & $71 \pm 8$ & $1324.4 \pm 0.6$ & $1.2 \pm 0.2$ & 0.88 \\
\hline $1344.27 \pm 0.05$ & $2.32 \pm 0.44$ & $4.14 \pm 0.80$ & $206 \pm 39$ & $1344.4 \pm 0.2$ & $2.4 \pm 0.2$ & 2.11 \\
\hline $1369.8 \pm 0.2$ & $0.29 \pm 0.05$ & $0.52 \pm 0.04$ & $26 \pm 4$ & $1370.5 \pm 0.7$ & $0.61 \pm 0.15$ & -0.58 \\
\hline $1546.9 \pm 0.2$ & $0.38 \pm 0.06$ & $0.68 \pm 0.11$ & $34 \pm 5.0$ & $1546.1 \pm 0.6$ & $0.59 \pm 0.12$ & 0.55 \\
\hline $1674.8 \pm 0.2$ & $0.23 \pm 0.06$ & $0.41 \pm 0.10$ & $20 \pm 5.0$ & $1678.1 \pm 0.7$ & $0.49 \pm 0.15$ & -0.44 \\
\hline $1758.9 \pm 0.2$ & $0.32 \pm 0.04$ & $0.57 \pm 0.07$ & $28 \pm 4$ & - & - & - \\
\hline
\end{tabular}

$E_{\gamma}$ is the gamma-ray energy, $P_{\mathrm{E} \gamma} / \varepsilon E_{\gamma} \cdot f_{\gamma}$ the net count in the gamma-ray peak divided by the full-energy-peak efficiency and the gamma-ray selfabsorption factor, $\mathrm{I}_{\mathrm{R}}$ the relative intensity of the gamma-ray and $\left\langle\sigma_{E \gamma}\right\rangle$ the fission neutron spectrum averaged isotopic cross section for gamma ray production at an angle of $90^{\circ}$ between neutron beam and detector determined with Eq. (3). R is the residual calculated by means of Eq. (11).

adelayed gamma ray of $\mathrm{In}-114 \mathrm{~m} 2$

b delayed gamma ray of In-113 m 


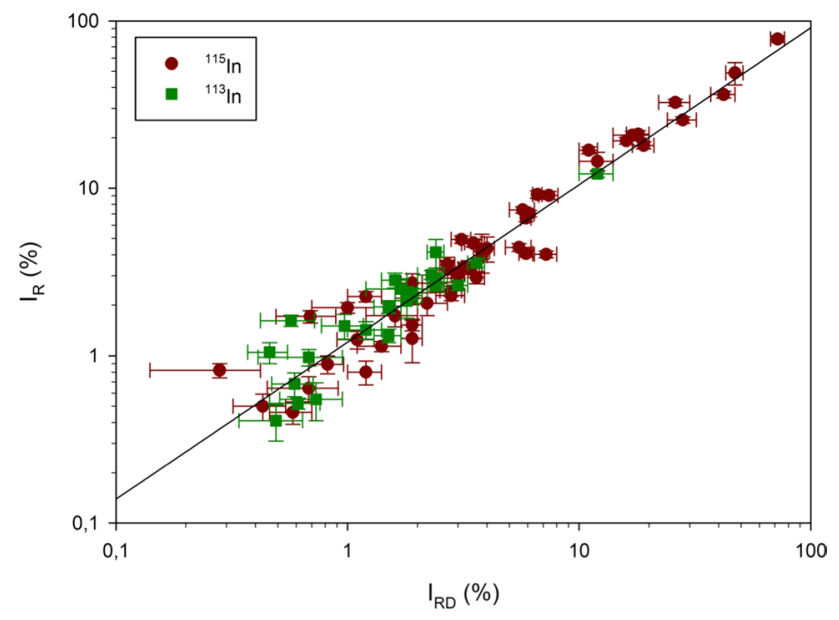

Fig. 6 Relationship between the relative intensities $I_{R}$ of the prompt gamma rays induced by fast neutron inelastic scattering on indium measured in this work and the relative intensities $I_{R D}$ tabulated in Demidov Atlas [7]. The solide line represents the fit of the data with Eq. (10)

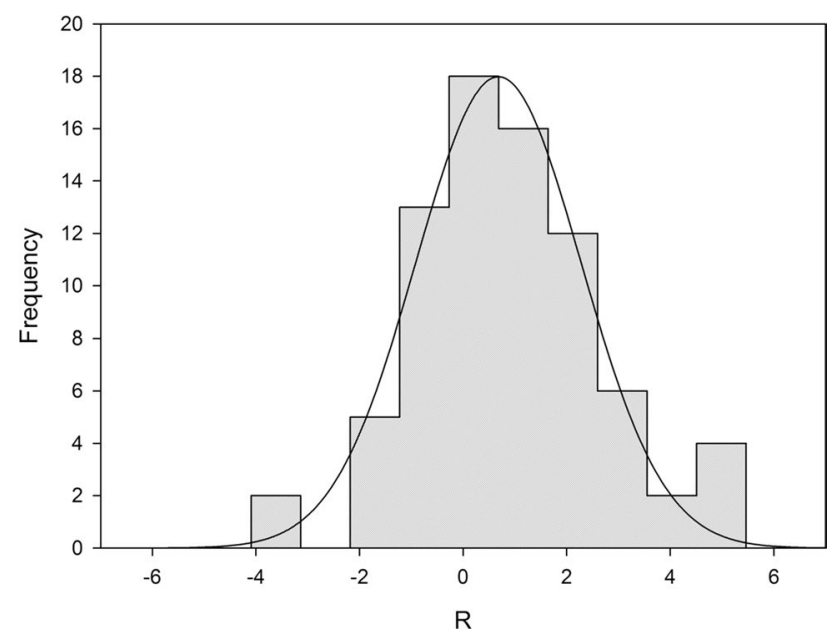

Fig. 7 Comparison of the relative intensities of the prompt gamma rays induced by fast neutron inelastic scattering on indium obtained in this work with the data tabulated in Demidov Atlas [7] in the form of a histogramm of the residuals $\mathrm{R}$ in unit of standard deviation $[\sigma]$ calculated with Eq. (11). The values of $\mathrm{R}$ are given in Tables 4 and 5. The solid line represents the fit of the data with a Gaussian

determine spectrum-averaged cross sections of $143 \pm 22$, $288 \pm 13$ and $194 \pm 18 \mathrm{mb}$, respectively. The relative intensities of the prompt gamma lines measured in our work agree reasonably well $(1.6 \sigma$ level) with the values given in the Demidov Atlas.

Funding Open Access funding enabled and organized by Projekt DEAL.
Open Access This article is licensed under a Creative Commons Attribution 4.0 International License, which permits use, sharing, adaptation, distribution and reproduction in any medium or format, as long as you give appropriate credit to the original author(s) and the source, provide a link to the Creative Commons licence, and indicate if changes were made. The images or other third party material in this article are included in the article's Creative Commons licence, unless indicated otherwise in a credit line to the material. If material is not included in the article's Creative Commons licence and your intended use is not permitted by statutory regulation or exceeds the permitted use, you will need to obtain permission directly from the copyright holder. To view a copy of this licence, visit http://creativecommons.org/licenses/by/4.0/.

\section{References}

1. Bernstein L, Brown $\underline{D}$, Basunia S, Hurst A, Kawano T, Kelley J, Kondev F, McCutchan E, Nesaraja C, Slaybaugh R, Sonzogni A, (2015) Nuclear data needs and Capabilities for Applications, White paper LLNL Report LLNL-CONF-676585, http://bang. berkeley.edu/events/ndnca/whitepaper

2. Romano C, Ault T, Bernstein L, Bahran R, Talou P, Quiter B, Pozzi S, Devlin M, Burke J, Bredeweg T, McCutchan E, Stave S, Bailey T, Hogle S, Chapman C, Hurst A, Nelson N, Tovesson F, Hornback D, (2018) Proceedings of the nuclear data roadmapping and enhancement workshop (NDREW) for nonproliferation, In: White paper ORNL/LTR-2018/510, https://www.nndc.bnl.gov/ nndcscr/documents/ndrew/NDREWProc_FINAL.pdf

3. Bernstein L, Romano C, Brown D, Casperson R, Descalle MA, Devlin M, Pickett C, Rearden B, Vermeuelen C, (2019) Final report for the workshop for applied nuclear Data activities (WANDA), White paper LLNL Report LLNL-PROC-769849.

4. Randriamalala TH, Rossbach M, Mauerhofer E, Zs R, Söllrad S, Wagner FM (2016) FaNGaS: a new instrument for (n, $\left.\mathrm{n}^{\prime}, \gamma\right)$ reaction measurements at FRM II. Nucl. Instrum. Meth. A806:370-377

5. Rossbach M, Randriamalala T, Mauerhofer E, Zs R, Söllrad S (2016) Prompt and delayed inelastic scattering from fission neutron irradiation - first results of FaNGaS. J. Radioanal. Nucl. Chem. 309:149-154

6. Ilic Z, Mauerhofer E, Stieghorst C, Zs R, Rossbach M, Randriamalala TH, Brückel T (2020) Prompt gamma rays induced by inelastic scattering of fission neutrons on iron. J. Radioanal. Nucl. Chem. 325:641-645

7. Demidov A, Govor L, Cherepantsev M, Ahmed S, Al-Najiar M, Al-Amili N, Al-Assafi N, Rammo N (1978) Atlas of gamma-ray spectra from the inelastic scattering of reactor fast neutrons. Atomizdat, Moscow

8. Hurst AM, Bernstein LA, Kawano T, Lewis AM, Song K (2021) The Baghdad Atlas: a relational database of inelastic neutronscattering $\left(n, n^{\prime}, \gamma\right)$ data. Nucl. Instrum. Meth. A 995:165095

9. MacFarlane RE, Kahler AC (2010) Methods for processing ENDF/B-VII with NJOY. Nucl. Data. Sheets. 111:2739-2890

10. Brown DA et al (2018) ENDF/B-VIII 0: The 8th major release of the nuclear reaction data library with CIELO-project cross sections, New Standards and Thermal Scattering Data. Nuclear. Data. Sheets. 148:1-142

11. Lemmel HD, McLaughlin PK, Pronyaev VG, (2001) ENDF/BVI release 8 (last release of ENDF/B-VI). Report No. IAEANDS-100, Rev. 11, Vienna: IAEA

12. OECD NEA Data Bank, (2020) JANIS Book of neutron-induced cross-sections https://www.oecd-nea.org/janis/book/book-neutr on-2020-09.pdf 
13. Zs R, Belgya T, Molnár GL (2005) Application of Hypermet-PC in PGAA. J. Radioanal. Nucl. Chem. 265:261-265

14. Zs Révay, Firestone RB, Belgya T, Molnár GL (2004) Prompt Gamma-ray Spectrum Catalog. In: Molnár GL (ed) Handbook of prompt gamma activation analysis with neutron beams. Kluwer Academic Publishers, Dordrecht/Boston/New York, pp 173-364

15. NuDat 2.8 National Nuclear Data Center, Brookhaven National Laboratory <https://www.nndc.bnl.gov/nudat2/>

16. Blachot $\mathbf{J}$ (2012) Nuclear data sheets for $A=115$. Nucl. Data. Sheets. 113:2391-2535

17. Fleming RF (1982) Neutron self-shielding factors for simple geometries. Int. J. Appl. Radiat. Isot. 33:1263-1268

18. Tatsuhiko $\mathrm{S}$ et al (2018) Features of particle and heavy ion transport code system (PHITS) version 3.02. J. Nucl. Sci. Technol. 55:684-690

19. Mughabghab SF, Divadeenam M, Holden NE, (2006) Atlas of neutron resonances - resonance parameters and thermal cross sections, $Z=1-100,5$ th Ed., ISBN 9780444520357 , Elsevier Science, March

20. Chu SYF, Ekström LP, Firestone RB, WWW Table of Radioactive Isotopes, database version 1999-02-28. http://nucleardata.nucle ar.lu.se/nucleardata/toi/

21. Pönitz W (1965) The spin of the 2 s isomeric state of In. Nucl. Phys. 66:297-300
22. Fettweis P, Sadasivan S (1973) On the decay of ${ }^{116 g}$ In. Z. Physik. 259:195-204

23. Alexander KF, Brinckmann HF, Donau F, Kissener HR (1963) Zur Isomerie des $\mathrm{In}^{116}$. Phys. Lett. 5:302-304

24. Shibata K et al (2011) JENDL-4. 0 A new library for nuclear science and engineering. J. Nucl. Sci. Technol. 48(1):1-30

25. Nuclear Data Center, (1996) Japan Atomic Energy Atomic, Tables of Nuclear Data https://wwwndc.jaea.go.jp/NuC/index.html

26. Erdtmann G (1976) Neutron activation tables. Verlag Chemie, Weinheim

27. Uddin MS, Sudár S, Hossain SM, Khan R, Zulquarnain MA, Quaim SM (2013) Fast neutron spectrum unfolding of a TRIGA Mark II reactor and measurement of spectrum-averaged cross sections: integral tests of differential cross sections of neutron threshold reactions. Radiochim. Acta. 101:613-620

Publisher's Note Springer Nature remains neutral with regard to jurisdictional claims in published maps and institutional affiliations. 